University of Wollongong

Research Online

Faculty of Social Sciences - Papers (Archive) Faculty of Arts, Social Sciences \& Humanities

$1-1-2016$

Down the methodological rabbit hole: thinking diffractively with resistant data

Gary Levy

Deakin University

Christine Halse

Deakin University

Jan Wright

University of Wollongong, jwright@uow.edu.au

Follow this and additional works at: https://ro.uow.edu.au/sspapers

Part of the Education Commons, and the Social and Behavioral Sciences Commons

Research Online is the open access institutional repository for the University of Wollongong. For further information contact the UOW Library: research-pubs@uow.edu.au 


\title{
Down the methodological rabbit hole: thinking diffractively with resistant data
}

\begin{abstract}
This article, part of a larger study, began with an inquiry into the ways a small group of preteen boys and girls with diagnosed eating disorders discussed their ideas and attitudes about healthy bodies in individual interviews. Despite applying some of the usual analytic procedures, the data yielded little of significance in relation to body and health discourses, or to gender differences. We therefore wondered whether our underlying epistemological lenses and methodological toolkit had prevented us from seeing and hearing what was happening with this particular cohort. By shifting from a predominantly feminist post-structuralist, socio-cultural approach to one more inflected with varieties of feminist post-humanism and post-qualitative thinking, the data came differently into focus, and invited closer consideration. Employing a diffractive analysis then allowed some fresh, unexpected salience in the data to become more apparent.
\end{abstract}

\section{Keywords}

resistant, diffractively, thinking, data, hole, down, rabbit, methodological

Disciplines

Education | Social and Behavioral Sciences

Publication Details

Levy, G., Halse, C. \& Wright, J. (2016). Down the methodological rabbit hole: thinking diffractively with resistant data. Qualitative Research, 16 (2), 183-197. 
Title: Down the Methodological Rabbit Hole: Thinking Diffractively with Resistant Data

Abstract: This article, part of a larger study, began with an inquiry into the ways a small group of preteen boys and girls with diagnosed eating disorders discussed their ideas and attitudes about healthy bodies in individual interviews. Despite applying some of the usual analytic procedures, the data yielded little of significance in relation to body and health discourses, or to gender differences. We therefore wondered whether our underlying epistemological lenses and methodological toolkit had prevented us from seeing and hearing what was happening with this particular cohort. By shifting from a predominantly feminist post-structuralist, socio-cultural approach to one more inflected with varieties of feminist post-humanism and post-qualitative thinking, the data came differently into focus, and invited closer consideration. Employing a diffractive analysis then allowed some fresh, unexpected salience in the data to become more apparent.

Keywords: diffractive methodology; feminist post-humanism; post-qualitative thinking; anorexia; children; resistant data 


\section{Introduction}

\section{The problem}

This paper emerged from a renewed engagement with interview data gathered as part of a larger project involving preteen girls and boys $(n=13)$ with a diagnosed eating disorder, and their mothers $(n=13)$. By the time we came to analyse the data for this paper, the project had already yielded a number of articles (e.g. Author B and others, 2013; Author B and others, 2014; Author C and others, 2014). The analysis that generated the previous papers had adopted a feminist post-structuralist epistemological framework, and utilised established tools of qualitative inquiry including semi-structured interviews, transcribing, coding and thematic clustering, immersion, critical data analysis and reflection.

We then turned our gaze to examine how these boys and girls engaged with discourses of health, food, bodies and appearance. We wondered whether this cohort had any 'interesting' or 'significant' things to say about food, health, body image, and the operations of bio-pedagogies (Author $C$ and other, 2009) that might reveal similarities or differences in relation to gender, subjectivity, socialisation, or schooling, given that both home and school contexts were recognised as likely sites where these processes were embodied and enacted.

We began by seeking out connections, patterns, themes, threads of continuity, points of contrast, hints of explanation, or hooks to various theoretical perspectives and other discourses in the data. Initially we were interested in a gender comparison but the data revealed little of significance or note. We had hoped that the relative dearth of existing literature on preteen girls and boys with eating disorders, coupled with the rigour we had maintained throughout the process of data analysis, might have exposed 
a gap that we could inhabit in some insightful ways. Yet the closer we looked at the data, and the more we resolved to find some hidden worthwhile meaning(s), the less we actually 'saw' of any 'real', or obvious significance. While certain isolated comments made by the children aroused a mild interest, they did not establish any themes or patterns that we could expand into meaningful analysis or discussion. We had come to accept that the transcript data related to the children's comments on health and body discourse had nothing further to yield, given our established methods and epistemological lenses. We were prepared to settle with this absence of significance, yet it continued to cause a mild irritation in us, like a bone in the throat. As MacLure (2006) pointed out, the bone caught in the throat cannot be easily 'spat out or swallowed. It is [therefore] a hopeful figure for a productively irritating method' (p. 731).

At this point we started to consider some tangential ways of thinking about our problem, or whether there might be some other productively irritating method we could deploy. The children had all been willing participants and generally forthcoming during interviews. We wondered, however, whether or not the data might have been successfully resisting our efforts to decode, unravel, and make them meaningful, in the same way that silence has been recognised as a form of resistance to analysis (MacLure, Holmes, Jones and MacRae, 2010). Our ways of seeing and attempting to understand the data were confounded, and the transcript data on which we had fixed our gaze were proving recalcitrant.

Having outlined our initial problem and the impasse that we had reached, we now present this paper in three discrete yet overlapping sections. First we outline the theoretical ideas that led to the jettisoning of our established epistemological framework and methodology. We then demonstrate how we applied this different way 
of thinking and analysing to fragments of our data set. Finally, we elaborate the implications of this approach in our discussion and continuing thoughts.

\section{Methodological Reorientation and Epistemological Shift}

In an attempt to clear the metaphorical bone from our methodological throats, we were jolted across to some of the innovations that have taken place recently within qualitative research (e.g. Jackson and Mazzei, 2012; Lenz Taguchi, 2012; MacLure, 2006, 2011, 2013a, 2013b, 2013c; Mazzei, 2013; Coleman and Ringrose, 2013). One of the key devices we utilised derived from MacLure’s (2006) conceptualisation of baroque method which intentionally 'resist[s] clarity, mastery, and the single point of view, be[ing] radically uncertain about scale, boundaries and coherence’ (p. 731), favouring interruption and inconclusion over consistency and certainty. Such an approach seeks to unsettle 'clear distinctions between subject and object' whereby 'objects are allowed to manifest their intransigent thingness or "objectity" in the face of the rule- or pattern-seeking propensities of conventional social science' (p. 734). The baroque approach encourages an 'obstructive potential' (p. 731) to come into productive play against more established social science methodologies, paving the way for different possibilities generated by other means.

The cabinet of curiosities was the baroque exemplar (MacLure, 2006, 2013c) we appropriated in our attempt to move beyond the impasse and onto more fertile ground for re-viewing the data. In the actual cabinets of late $16^{\text {th }}$ and early $17^{\text {th }}$ century Europe, 'contents were by no means "transparent displays” open to the masterful gaze of a detached observer' (MacLure, 2006: 737). MacLure explains further, 
Their contents were concealed in nested drawers, shelves, niches and boxes, behind internal doors, frames and partitions. These contents often included devices that distorted or played with reality: lenses, mirrors, optical games, paintings and clockwork automata. Thus the cabinets played with representation and reality—nesting one representation within another, producing doubles and deferral, putting reality into suspension (p. 737).

The whole process of viewing the displays in the cabinet is relevant here, the different ways in which doors opened and closed, revealing artefacts from different perspectives, and within different timeframes. The cumulative effect was one of intensification and exhilaration that 'sets perception, cognition and imagination in motion' (p. 737). We were careful not to import the details of the actual historical cabinet too literally into a new methodological template, being mindful too of Deleuze's movement cautionary notes on metaphors in the literary context, given their capacities can tempt, force, and limit meaning (Marks 1997). Nevertheless, MacLure’s (2006) conceptualisation and explanation usefully disturbed the habitual analytic modes and lenses with which we had been viewing the data. The disturbance invited us to recognise more the odd, off-centre, recessed, and oblique ways in which different comments made by the cohort of children with eating disorders sat near, or in relation to each other, while also presenting differently to us. This fresh methodological endeavour could potentially provide us with a way to loosen up the resistance within the data.

We thus began to re-think our way of searching this data, or to re-search our way of thinking about the young people in our study. We began to retreat (ie recede) from our engagement with the process, and to take a break (ie recess) from our established connections with the data. This then allowed us to look deeper into, and differently at, 
the data until they suggested some fresh angles from which they could be viewed, perhaps becoming more fully or differently revealed in the process.

The revised process prompted us to give closer consideration to some of the recent developments in feminist epistemology (e.g. Barad, 2007; Grosz, 2010; Lather, 2013; Lykke, 2010); Deleuzean approaches to qualitative and educational research (Jackson and Mazzei, 2012; Lenz Taguchi 2010, 2012) and post-foundationalism (MacLure, 2006; Taylor and Ivinson, 2013). These ideas could provide new theoretical support for our engagement with the data, while simultaneously disturbing our habitual ways of analysing and making sense of interview data. Notions of diffraction, entanglement, becoming, and mattering assumed more active and central importance, as will be made evident in the remainder of this paper. As our curiosity fuelled our thinking, fragments of interview transcripts sitting in various recesses of the metaphorical cabinet of our inquiry, began looking back at us, also curious, wondering, and coaxing. Seeking ways for the data to become more of 'a constitutive force, working upon the researcher [potentially] as much as the researcher works upon the data (Hultman and Lenz Taguchi, 2010: 527), we began to look differently into our cabinet of data curiosities. This left us with a 'shaky poise at the threshold of the unknown’ (MacLure, 2006: 737).

The threshold arrives when the limits of knowing, or particular ways of knowing, are reached (Jackson and Mazzei, 2012). An inability to make any special sense of the interview transcript data fragments took us to the limits of our ways of analysing data and generating any new knowledge as feminist post-structuralist researchers. This opened the data to mattering in new ways, especially certain turns of phrase that were uttered spontaneously by some of the preteen boys and girls with eating disorders during the interviews. The fact that we had hitherto been confounded by these 
utterances became the very prompt we needed to become, like Alice in her Wonderland adventures, 'curiouser and curiouser' (Carroll, 1983: 33).

Two further ideas fuelled our curiosity through this process. The first related to Barad's (2007) notion of meaning as being entangled with all other matter, operating through the materio-discursive aspect of language. For Barad, "Discursive practices and material phenomena do not stand in a relationship of externality to each other; rather, the material and the discursive are mutually implicated in the dynamics of intra-activity' (p.152, italics in original). This assumed special significance in relation to the interview data fragments. Barad invited us to engage with the idea that the words spoken by the children (and the interviewer) were not, therefore, 'a property of individual words or groups of words but an ongoing performance of the world in its differential dance of intelligibility and unintelligibility’ (p.149). This allowed us to reconsider how the 'matter' of what the children said, could come to matter differently in terms of its meaning for us.

The second idea re-shaping our thinking came from Deleuze's concept of the 'event' and how this could be related to the interview process. For Deleuze, events are, expressed by means of language, in statements, but they are attributes of bodies and physical states of affairs... On this account, events are the epiphenomena of corporeal causal interactions: they do not affect bodies and states of affairs but they do affect other events, such as the responses and actions of agents. Pure events are both the expressed of statements and the 'sense' of what happens (Patton 1997, np).

In our (re) engagement with the interview data, we attempted to ascribe more embodied physicality to the children and what they expressed. We also sought to 
allow the statements of the children to affect our responses in order to glean better, or differently, the 'sense' of what had been said.

\section{Curiously re-engaging with the data}

When asked the standard question to describe what an unhealthy body looked like, Maddy [aged 10] replied:

'Maybe someone who eats too much, or someone who eats too little, or someone who’s really depressed.'

While our question placed an implicit emphasis on the physical body, Maddy offered a response that challenged, or confounded, this assumption. This response caught our attention, fuelled our curiosity, and suggested that we needed to rethink our own formulations. Maddy’s comments about body size eschewed the common physical descriptors of appearance such as fat, thin, obese, overweight, skinny, anorexic and couch potato. Instead, Maddy focused on the process of eating, and the volume of food consumed, giving agency both to the person eating, but also to the matter of food itself as a possible source of depression. Maddy’s emphasis on process and agency conjures a dynamic, fluid, and changing set of conditions pertaining to a healthy body and its appearance, different to a clinical construction of the body as static, defined, bounded and nominal. Despite, or perhaps even because of having a diagnosis of anorexia, Maddy acknowledged negative consequences associated with eating either too much or too little. We tentatively wondered or imagined (MacLure, 2006) whether there was some awareness in Maddy, that if one is able to eat enough in a sustained way, then one will be sustained in a healthy way, or perhaps endowed with greater healthiness. 
Maddy described an unhealthy body as ‘someone who’s really depressed’. Again, there is agency and movement in the reference because a person doesn't 'have depression' but rather, they 'are depressed'. Someone who 'is' depressed has their entire being charged with this condition, compared to someone who has, somehow, either taken possession of depression, or had it delivered to them. Medical models construe depression as a mental health problem and individual pathology. By contrast, Maddy's construction is ontological and opens up the potential for release, expansion, elevation and re-animation. These are the latent others of being depressed, perhaps tangled and concealed within the state of being. By allowing the pathological to dominate the ontological, we could have easily overlooked an important concern with the interior that Maddy's comment points to. There is also more of an interior bias in Maddy's comment, that is a concern for the way things are within the self, rather than how they physically appear.

Maddy's comment runs counter to many of the wider social discourses that focus on the exterior factors, for example what we do (e.g. eat), rather than how we feel. It also throws up an unwitting challenge to the conventional mind-body binary that underpins much of Western philosophy, the natural and social sciences, and everyday discourse. Her conceptualisation of an unhealthy body unequivocally includes someone with a clinical, mental-emotional illness, such as depression. Thus, Maddy seemed (instinctively?) attuned to how mind and body intra-act, or engage intraactively (Barad, 2007; Lenz Taguchi, 2010, 2012). In doing so, her words echo Lenz Taguchi’s (2010) call to acknowledge how ‘somatic illnesses emerge from emotional events that will profoundly affect the body in different ways’ (p. 4).

Freya's [aged 11] response to the same question about an unhealthy body also blurred the mind-body binary. 
'And you need to look like you're...being happy also helps with a health body, because it helps with how your emotions feel'.

Like Maddy, Freya drew on the non-physical dimension to support a comment she was making about the body. Without hesitation or apology, Freya bound the feeling of happiness to the condition of physical healthiness. There are obvious claims of union, or indivisibility here, between mind/body, thought/feeling and action/sensation, that all look like sharing a singular envelope, or process of continuous enfolding (Deleuze, 1993). For Freya, happiness is embodied or enfleshed, bodies can be happy, and emotions feel. There are intimations in Freya's mingling of healthy bodies with emotions that point to the fluid interplay of agency and matter acting within an entwined, enveloped, or entangled experience that cannot be easily reduced to either the physical/sensational, nor just the mental/emotional (Barad, 2007). These curious turns of phrase (by Maddy and Freya) point to varied and multiple manifestations of what Merrell (2003) refers to as the 'bodymind', his attempt to account linguistically for the unruptured nature of experience.

\section{Breaking new ground}

Even with nothing more than a set of linguistic resources typical for their ages (9-12), the girls and boys with eating disorders in our study found occasions to let their bodyminds talk through language in slightly off-beat, curious, and intriguing ways. Other comments by Freya also attracted our attention. Following a series of consultations with, and adjusted meal plans from a dietician, Freya talked about becoming more and more confused in relation to eating, and less able to eat anything. Freya said the dietician had 'twisted my brain' and that further appointments were 
required with the doctor who was 'trying to untwist my brain from what she [the dietician] has taught me, because I listen and I drill that into my brain'. For Freya, the turmoil and confusion generated by a series of encounters with her dietician and doctor was captured in her experience of a 'twisted brain'. The twisted brain reminds us of the arbitrary and problematic divisions of body/mind, and the mental/material, and how these can be subverted by children with atypical and surprising articulations of their lived and embodied experiences. Freya neither referred to her mind, nor her head, as being twisted or confused, images more familiar to us from colloquial speech. Even if Freya was slightly skewing a more familiar metaphor, she offered a potent image of a vital bodily organ literally tied tightly around itself, crippling its proprietor, and forcing a lurch towards another form of professional help to assist with its disentanglement. This assistance was obviously necessary for Freya but at the same time, her description clearly presented a bodymind, or thickened subjectivity (Juelskjaer, 2013) characterised by complex and multifaceted entanglements.

\section{From 'twisted brain' to other 'stuff'}

There are echoes of Freya's twisted brain in the following exchange with Louis [aged 12]:

Interviewer: 'Well tell me, when did you start getting sick?

Louis: 'Like sick as in the brain or as in like underweight?'

Interviewer: 'Oh well, that's a good question. I don't know which one I mean'.

After acknowledging the merit of Louis' question, our interviewer acknowledged she was unsure what the question meant. Nothing was made of this in the field notes, nor 
in the early rounds of coding. Yet this exchange with Louis is important for a number of reasons, firstly because of the way he disturbed the usual interview pattern of question/answer by answering the question with another question. In doing so, Louis also disrupted the power relationship operating between the researcher/subject or adult/child, by inverting the roles. This assumption of a position of power by Louis, one that flummoxed the interviewer by catching her off guard, invited closer consideration. On the one hand, Louis’ question can be read as simply reproducing the classic mind (brain) - body (underweight) binary. On the other hand, Louis’ response disrupted the very same binary that appeared to have been operating, albeit unconsciously, in the researcher. It could be claimed that Louis’ answer/question hinted at what Barad (2007) refers to as 'the inherent indeterminacy of bodily boundaries' (p.157). This, in turn, created an impasse or obstacle in the researcher, who was nevertheless able to acknowledge the validity of Louis’ reply, and the instability of her initial question. Barad (2007) argues that the 'deep significance of a diffractive pattern' is the way it operates as a material practice for 'making a difference, for topologically reconfiguring connections' (p.381, italics in original). Louis' reply can be seen as having such potential to destabilise the conventional mind/body binary, while also hinting at other possible (albeit unknown) reconfigurations. Such a diffractive gesture is typical for its 'effects of interferences, where the original wave partly remains within the new after its transformation' (Lenz Taguchi, 2012: 271).

Louis’ answer also spells out very clearly his assumption that anorexia is a psychophysical phenomenon. This is not a contentious view. Various models for research into anorexia identify the complex combination of biological, mental, psycho-emotional and socio-cultural factors operating within each case. What is 
interesting about Louis' comment is the way it was spoken through him as a reminder to the interviewer, that mind and body are much more complexly entwined and entangled than is often assumed. Within a different, diffractive way of thinking, the comment then also spoke differently to those of us involved in looking at the data. We wondered whether, as researchers, we tended to focus too much on learning about our subjects, rather than learning from them, or through them, or with them?

When commenting and reflecting on the impact of his eating disorder, Louis suggested that, 'if you feel hungry then eat more; if you don’t feel hungry, or if your feel full, don't eat more'. The logic here is disarmingly simple. It cuts across, and potentially undermines layers of complex individual and cultural history and discourse around food, health, eating and body image. The simplicity of the advice belies and conceals a greater profundity. Louis' statement compels us to stop and think why and how it is that we, assuming there is enough food available, may have lost touch with our own instinctive appetite, or hunger drive. Despite, or perhaps because of his experience of anorexia, Louis appears to be aware of this instinct in himself, and is able to articulate it unequivocally,

'Well I just say well, food is good, just don’t eat too much and remember, if you feel hungry have something, because what your gut tells you, you need to do. Your gut is always right'.

These comments could be read in several ways, while also conceding that Louis may have reproduced what he had heard and learnt from the discourses favoured by his expert team of doctors, nutritionists and other carers. From one angle, Louis suggested that our gut/stomach/digestive tract is the best guide for our appetite and patterns of food consumption. We eat when we feel hungry as we need to address that 
sensation and satiate the urge. Looking/listening a little more sideways however, we could also see/hear Louis telling us that the gut is not just something we respond to, but also something that directs us and tells us what we need to do. Even if Louis' comments about the gut are intended to be food-specific, they could also be allowed to reverberate in relation to other human behaviours. Bergson's remark chimes in usefully here, reminding us that, 'instinct alone can give the concrete feel of knowledge’ (cited in Reid, 1972: np). There are, therefore, epistemological implications and consequences in Louis' statement. This is reinforced by his conviction that 'your gut is always right'. There are even moral overtones here, evidenced by his direct statement about what is good and right.

Following Louis’ advice to follow the gut and to eat only when either hungry or not already full of food, our interviewer responded with a rhetorical question, 'So listen to your body?' to which Louis replied, 'Yes, and listen to your body, don’t listen to your person'. Initially, this exchange looked to contradict our analysis of the body and mind that tended to be artificially separated by language. However, is 'listen [ing] to your body' equivalent to 'your gut is always right'? It is easy to slip into the binary trap and assume 'gut equals body', and this is the slip the interviewer appeared to make in her response. Louis chose to affirm the split imposed by the rhetorical question, but then instantly offered a point of difference/differentiation between 'your body' and 'your person'. Without disputing or dismissing the encapsulation of his experience and learning as 'listen to your body', Louis introduced his conception of 'your person' as being more, or perhaps other than, just a body. In doing so, Louis’ differentiation of 'person' from 'body' aligned with the Deleuzean notion of difference as a 'positive 
force of differentiation and transformation’ (Lenz Taguchi, 2012: 269). Louis was instantly resistant to being reduced to just a body and, within the limits of his language resources, identified his 'person', as being productively other than his 'body’ alone.

Benjamin [aged 11], during his interview, recalled an incident when his class was learning about puberty. Benjamin had used his pre-existing knowledge to draw a picture of 'a man's lower part with hair around it' to demonstrate his knowledge. This picture became a source of some amusement for the teacher, and apparent embarrassment for Benjamin. When recalling the situation and the context, Benjamin matter-of-factly announced that given the age and stage of his peer group, learning about puberty was highly appropriate. As Benjamin put it, 'because we're getting to that age where stuff kicks in’. This time, our interviewer was not so disarmed, and endorsed Benjamin’s claim:

'Stuff kicks in. Yeah, for sure’.

This succinct statement from Benjamin also took up residence in a new recess in our cabinet of curiosities when we re-engaged with the transcript data further for this paper. 'Stuff kicks in'. It is hard to imagine a more pithy encapsulation of the myriad experiences, emotions, developments, encounters, sensations, impulses, desires, reactions, thoughts, eruptions, dreams, phantasies, murmurings and exchanges that become entangled and equally, entangle the process of becoming both during puberty, and beyond. Benjamin's phrase was comprehensive in its reach, while at the same time issuing a cautionary note to anyone wanting to break down or compartmentalise 
all the 'stuff' and its processes. Nevertheless, when puberty is taught in schools and at home, this is what tends to happen. Bodies go through changes which usually bring accompanying changes in how we feel. A small concession to the integrity of bodymind perhaps, but the body is usually then separated and broken up into various systems (e.g. skeletal, endocrinal, reproductive-sexual), as is the mind (new ways of thinking, cognising, relating). None of this comes close to the scope and sweep of Benjamin’s statement, which is replete with dynamism and implicitly allows for variation, difference and differentiation, uncertainty, flux and change. In either an educational or familial context, Benjamin's words could act as a motif and catalyst for promoting non-binary, complex, intra-active ways of thinking and hence, knowing.

As is evident from the above commentary, we were 'enchanted' (Hultman \& Lenz Taguchi, 2010: 540) by Benjamin’s comment. We then wondered (MacLure, 2013a) about Benjamin’s reference to ‘a man’s lower part'. The comment had been passed over in earlier coding as seemingly insignificant and without import. However, when we allowed it to sit again, yet differently, in our cabinet of curiosities, the reference invited closer consideration. It appears that Benjamin had picked up on discourses referring to the genitalia as private parts, and the body as having upper and lower sections. The folly of such arbitrary and artificial dichotomies is revealed sharply in Benjamin's creation of 'a man's lower part'. We know what meaning Benjamin most likely intended by this reference, and mightn’t have otherwise stopped to think more on it, except that we had become interested in thinking other-wise. Once we did, we awoke to the fact that men do not have an equivalent 'upper part' and hence, the whole schema had to be called into question. We came to regard the reference to 'a man's lower part' as a slippage. As such, it then presented as the obstacle necessary to 
diffract our thinking from its conventional path, and to permit other possibilities for bodymind being and becoming. These possibilities exist outside, or beyond the norms and restrictions established by dichotomies of upper/lower, part/whole, and even private/public. It was the seemingly very minor and unremarkable qualities to Benjamin's reference that provided us with an opening towards some different meaning that mattered, and some matter that meant something other than what conventional biological discourse suggested.

\section{Further points of difference}

One further example relates to a fragment of data provided by April [aged 12]. In response to the standard invitation to find four words to describe a healthy body, April replied,

'Nourished', to which the interviewer responded, 'Great word'.

April then continued, 'Fit, healthy, and special'.

On this occasion, our interviewer considered April's word choice worthy of acknowledgement and amplification. 'Nourished' suggests possible engagement with the discourse of nutrition that April may well have picked up either at school, home, or the wider community. Along with the resonance of a healthy eating discourse, 'nourished' also has wider and deeper connotations of nurturing, enriching, enlivening, motivating, valuing and even cherishing [Latin nutrire]. These qualities, while being anchored in the material practices of food consumption and exercise, simultaneously suggest an intersection and overlay with emotional, interpersonal, even spiritual dimensions. A healthy body may well be one that is suitably 
'nourished', but we needed to think more, differently, and other-wise about some of the hidden connotations of this word. The point to make is that 'nourished' permits entanglements that subvert conventional boundaries and binaries. While our interviewer acknowledged and praised the potency of the word, we returned and researched this extract with a diffractive mode of thinking in order to appreciate more fully why it was (felt by the interviewer to be) such a 'great word' to choose.

The process generated a similar outcome in relation to April's equating a healthy body with being 'special'. By allowing this word to diffract or break away from our conventional understanding, we realised that 'special' is a bold statement about the natural form and beauty of the species [Latin specialis]. Of all the possible words April could have chosen, she found 'special' as one of four that suitably expressed her feeing and understanding of what a healthy body meant to her. In doing so, April was announcing something about the magnitude of a healthy body, re-membering and reminding us how it inheres in our very species. Our interviewer requested April elaborate on what she meant:

Interviewer: 'Special-that's interesting, what do you mean?' April: 'Different, you know, not the same as everyone else. Different'. Interviewer: 'Yeah, interesting. Okay'.

On first reading, we saw April as making a statement about her uniqueness or desire to be recognised as such. On further and closer examination of this curiosity however, we started to see and hear other things going on. For April, a healthy body equalled 'different', and 'different' meant 'not the same as everyone else'. She added rhetorical force with her 'you know', and gave further weight to her statement by repeating 'different' at the other end of her reply. As such, it is difference that 
bookends her explanation of what she means by 'special', inhering and entangled in her species, thereby invoking the speciality of her species, and her species-ness. This kind of difference is a very positive, productive difference, one that generates actions, intra-action, and qualities that are 'not the same as everyone else'. Perhaps not the same as anyone else either?

The more we allowed this response to break away from, and overlap with its implied and possible meanings, the clearer it became to us that April was incorporating [Latin incorprare] herself in her answer, while at the same time highlighting the value of a diffractive methodology. In this response, we could simultaneously see an instance of the spontaneous irruption of a materio-discursive truth about April, her species commonality/common speciality, and a way of letting this truth speak through her, and be heard. It was only be allowing these data fragments to sit/recess differently, that our curiosity could also square up with the data-fragment in previously unthought ways.

\section{Continuing thoughts}

As researchers, the challenge for us was to yield to our 'perplexity' (MacLure, 2013b: 662) in favour of reading the data more as sense-event in which language remains, in the process, 'non-representational, non-interpretive, a-signifying, a-subjective, paradoxical and embroiled with matter' (p. 663). This approach might smack of primordial soup if MacLure didn't also stress ‘the fact that language is in and of the body; always issuing from the body; being impeded by the body; affecting other bodies’ (p.663-4). To which we might usefully add that not only does language issue 
from the material body, but that same body or bodymind, can also shape, limit, bend, impede and extend the matter of language.

Barad (2010) also makes an important qualifying point in relation to entanglements, suggesting that they are 'not a name for the interconnectedness of all being as one, but rather specific material relations of the ongoing differentiation of the world' (p. 265). The notion of entanglement is adopted by Lenz Taguchi when articulating a diffractive and Deleuzean approach to analysing research data. Lenz Taguchi’s (2012) interest is, in part, to permit more engagement from, and insinuation of the researcher's bodymind, along with other animate and inanimate matter, in the process of diffractive processing. While taking a lead from this approach, we became more focused on identifying ways in which the bodymind and already-entangled material realities of the subjects irrupted through some of the language they used in response to questions about themselves, health and bodies.

We assumed the role of what Deleuze and Guattari (1988) referred to as 'becoming minoritarian' (p. 106) wherein our commitment was to 'thinking otherwise and away from norms and rigid power-producing habits of thinking by ways of new encounters and engagements' (Lenz Taguchi, 2012: 272). Through this process, we found ourselves 'being used by thought' (Lather, 2013: 639), rather than having to do the thinking in order to make meaning. Being used by thought meant having to resist succumbing to our established ways of framing, viewing, analysing and theorising research data; it meant being prepared to yield to the discomforts that accompanied 'not knowing' and 'not understanding; it meant opening ourselves to the prospect of certain meanings, even truths, being hidden or entangled within fragments of data that 
had not revealed themselves using our established methodological tools, and that had left us on the verge of 'closing the book' on the data.

Being used by thought also meant assuming a different onto-epistemological stance in relation to the data fragments, inviting them to open us up to what they still had to say. This required us to stay and work with the process long enough for the resistance in the data (but equally in our researcher-selves) to loosen up and break down sufficiently, to then permit some fresh and different insights to emerge. Furthermore, this stance permitted an ethical component, in that our diffractive approach allowed some continuous respect to be shown towards what the children had said in the interviews. This kind of re-spect, this way of looking back, looking again, looking differently [Latin respectus] turned out to honour more fully some things the children had said, but also, perhaps, the way they experienced themselves in the world, by resisting, being and acting beyond binaries (intra-acting); embracing and embodying difference; entangled in worlds that do not readily separate what they think, from how they feel, from what they say, from what they eat, from how they look, to how they communicate. In this way too, the fundamentally ethical impulses driving Barad's (2007, 2010) project came into fuller light.

\section{Conclusion}

The demonstration of diffractive processing offered in this paper points to some possible ways in which thinking, and being thought differently, can work to disrupt habitual modes of hearing and seeing research data, with the accompanying biases and blinkers that these habits often entail. The need for caution and concern has been identified previously by feminist post-structuralist scholars researching the field of eating disorders (e.g. Malson, 1998; Malson and Burns, 2009). However these 
accounts have focused more on critiques of the existing socio-cultural conditions and the 'violences of pathologicalisation' (Malson and Burns, 2009: 4) that are embedded in the responses to, and treatments of the condition, especially for women. Little attention has been given to younger populations afflicted with eating disorders, nor what they have to say for/about themselves.

While we had largely dismissed the data as unrevealing and insignificant in relation to our inquiries into gender, bodies, and health, a few fragments 'productively puzzled' us (Dyke, 2013: 161). The disruption of categories based around traditional binaries was one particularly noteworthy effect of this process, especially the classic mind/body split, but also the physical/mental, upper/lower, part/whole dichotomies. We realised that some of the nuances and implications of this shadowy knowledge can be overlooked or dismissed, either when coding for certain established nodes or themes, or when seeking to represent/interpret data within a given analytic framework. MacLure (2013c) noted the tendency within coding to 'take you "away" from the data-from their detail, complexity, singularity’ (p. 169).

Lenz Taguchi (2010) argued that diffractive thinking 'requires us to engage in an event of reading and becoming-with the data' (p. 272, italics in original). Through our examples it is possible to see the subtle yet problematic ways in which language, thought and matter operate to both expand and restrict our ability to account for lived, embodied experience. We re-routed some of our conventional ways of analysing and interpreting the research data in order to see/hear what else/other may have been lying in the cracks and recesses of both the transcript data and our thinking. Our small 
examples point to the strength of such an approach, the main aim being to 'give a [new or different] direction’ to thinking (Mazzei, 2013: 108).

Methodologically, rather than turning in any one direction towards language, or materiality, or bodies, we found ourselves re-turning differently/diffractively to the data, and allowing the data to re-turn itself differently to us. Most notably, we became more keenly aware of tendencies in our approach to data collection, coding, and analysis that unconsciously reproduced and perpetuated some of the problematic binaries that have long inhabited and haunted western discourse. By the end of our research, it was apparent that diffractive modes of thinking and analysis invite and permit different and unintended outcomes and possibilities for qualitative inquiry. We were buoyed by the insights and possibilities generated by small shifts in the way we approached and thought about our data. We remain encouraged by our discoveries to pursue further explorations and incursions into and through these methodological hinterlands, and beyond to the fresh epistemological, ontological and ethical vistas they open up. 


\section{References}

Author C and other (2009) details withheld for peer review

Author B and C (2013) details withheld for peer review

Author B and other (2014) details withheld for peer review

Author C B and other (2014) details withheld for peer review

Barad KM (2007) Meeting the universe halfway: quantum physics and the entanglement of matter and meaning. Durham: Duke University Press.

Barad KM (2010) Quantum Entanglements and Hauntological Relations of Inheritance: Dis/continuities, SpaceTime Enfoldings and Justice-to-Come. Derrida Today 3(2): 240-268.

Barad K (2012) Interview with Karen Barad. In R Dolphijn and I van der Tuin (eds). New Materialism: Interviews \& Cartographies. University of Michigan, Ann Arbor: Open Humanities Press, 48-70.

Braidotti R (2013) The Posthuman. Cambridge, UK: Polity Press.

Carroll L (1983) Alice’s Adventures in Wonderland and Through the Looking Glass. Harmondsworth Middlesex: Puffin Books.

Coleman R and Ringrose J (eds) (2013) Deleuze and Research Methodologies.

Edinburgh: Edinburgh University Press. 
Deleuze G (1993) The Fold. Leibniz and the Baroque. London: The Athlone Press.

Deleuze G and Guattari F (1988) A Thousand Plateaus: Capitalism and Schizophrenia. Translation and Foreword by Brian Massumi. London: Continuum. Grosz E (2010) The Untimeliness of Feminist Theory. NORA-Nordic Journal of Feminist and Gender Research 18(1): 48-51.

Hultman K and Lenz Taguchi H (2010) Challenging anthropocentric analysis of visual data: A relational materialist methodological approach to educational research. International Journal of Qualitative Studies in Education 23(5): 525-542.

Jackson AY and Mazzei LA (2012) Thinking with Theory in Qualitative Research. Viewing data across multiple perspectives. Oxon: Routledge.

Jackson AY and Mazzei LA (2013) Plugging One Text Into Another: Thinking With Theory in Qualitative Research Qualitative Inquiry 19 (4): 261-271

Juelskjaer M (2013) Gendered subjectivities of spacetimematter. Gender and Education 25(6): 754-768.

Lather P (2013) Methodology-21: what do we do in the afterward? International Journal of Qualitative Studies in Education 26(6): 634-645.

Lather P and St. Pierre EA (2013) Post-qualitative research. International Journal of Qualitative Studies in Education 26(6): 629-633.

Lenz Taguchi H (2010) Going beyond the theory/practice divide in early childhood education: introducing an intra-active pedagogy. Abingdon, UK: Routledge.

Lenz Taguchi H (2012) A diffractive and Deleuzian approach to analysing interview data. Feminist Theory 13(3): 265-281. 
Lykke N (2010) The Timeliness of Post-Constructionism. NORA-Nordic Journal of Feminist and Gender Research 18(2): 131-136.

MacLure M (2006) The bone in the throat: some uncertain thoughts on baroque method. International Journal of Qualitative Studies in Education 19(6): 729-745.

MacLure M, Holmes R, Jones L. and MacRae, C (2010) Silence as Resistance to Analysis: Or, or Not Opening One’s Mouth Properly. Qualitative Inquiry 16(6): 492500.

MacLure M (2011) Qualitative Inquiry: Where Are the Ruins? Qualitative Inquiry 17(10): 997-1005.

MacLure M (2013a). The Wonder of Data. Cultural Studies <> Critical Methodologies 13(4): 228-232.

MacLure M (2013b) Researching without representation: Language and materiality in post-qualitative methodology. International Journal of Qualitative Studies in Education 26(6): 658-667.

MacLure M (2013c) Classification or Wonder? Coding as an Analytic Practice in Qualitative Research. In: Coleman R and Ringrose J (eds.) Deleuze and Research Methodologies. Edinburgh: Edinburgh University Press, 164-183.

Malson H (1998) The Thin Woman. Feminism, post-structuralism and the social psychology of anorexia nervosa. London: Routledge.

Malson H and Burns M (2009) Re-theorising the slash of dis/order: An introduction to critical feminist approaches to eating dis/orders. In: Malson $\mathrm{H}$ and Burns $\mathrm{M}$ (eds) Critical Feminist Approaches to Eating Dis/Orders. London: Routledge, 1-6. 
Marks J (1997) Deleuze and literature: Metaphor and indirect discourse, Social Semiotics 7(2): 233-246.

Mazzei LA (2013) Desire Undone: Productions of Privilege, Power and Voice. In:

Coleman R and Ringrose J (eds) Deleuze and Research Methodologies. Edinburgh:

Edinburgh University Press, 96-110.

Merrell F (2003) Sensing corporeally: toward a posthuman understanding. Toronto: University of Toronto Press.

Patton P (1997) The World Seen From Within. Theory \& Event 1(1):

http://muse.jhu.edu/journals/theory_and_event/v001/1.1patton.html

Reid CL (1995) The Free Voice. A Guide to Natural Singing. New York: Joseph Patelson Music House.

Taylor CA and Ivinson G (2013) Material feminisms: new directions for education. Gender and Education, 25(6): 665-670. 